\title{
Mammary-digital-nail syndrome
}

INSERM

\section{Source}

INSERM. (1999). Orphanet: an online rare disease and orphan drug data base. Mammarydigital-nail syndrome. ORPHA:238744

Mammary-digital-nail syndrome is a syndromic limb malformation characterized by congenital onychodystrophy/anonychia, brachydactyly of the fifth finger, digitalization of the thumbs, with absence or hypoplasia of the distal phalanges of the hands and feet in association with juvenile hypertrophy of the breast with gigantomastia in peripubertal females. 